\title{
White Matter Injury of Prematurity: Its Mechanisms and Clinical Features
}

Young Ah Lee

Division of Pediatric Neurology, Department of Pediatrics, Beaumont Hospital, Oakland University School of Medicine, Royal Oak, Ml, USA

Received: May 2, 2017

Revised: July 19, 2017

Accepted: July 25, 2017

Corresponding Author

Young Ah Lee, MD, PhD

Division of Pediatric Neurology, Department of

Pediatrics, Beaumont Hospital, Oakland University

School of Medicine, 3555 West 13 Mile Road, Suite

N120, Royal Oak, Ml 48073, USA

Tel: +1-248-551-7370

Fax: +1-248-551-7373

E-mail: young.lee2@beaumont.org
A developing central nervous system is vulnerable to various insults such as infection and ischemia. While increased understanding of the dynamic nature of brain development allows a deeper insight into the pathophysiology of perinatal brain injury, the precise nature of specific fetal and neonatal brain injuries and their short- and long-term clinical consequences need special attention and further elucidation. The current review will describe the pathophysiological aspects and clinical significance of white matter injury of prematurity, a main form of perinatal brain injury in premature newborns, with a particular emphasis on its potential antenatal components.

Key Words: Prematurity; Injury; White matter; Periventricular leukomalacia
Injuries to the brain can be fatal or lead to catastrophic events regardless of the age of patients, and brain injuries of newborns can be coupled with lifelong intellectual or motor deficits as in cerebral palsy. ${ }^{1,2}$ Hypoxia-ischemia (H-I) has long been considered one of the major mechanisms of perinatal brain injuries, ${ }^{3}$ and the term hypoxic ischemic encephalopathy (HIE) has been widely used. ${ }^{4}$ HIE is defined as an acute encephalopathy caused by intrapartum or late antepartum brain hypoxia and ischemia mostly in term babies. ${ }^{5}$ In HIE, compromised oxygen and glucose supply to the brain cells leads to cellular energy failure, ${ }^{6,7}$ and a large body of evidence indicates a clear association between HIE and neurodevelopmental problems in surviving infants. ${ }^{8}$

Fetal development is a dynamic process, and the changes in the anatomical constitution and the physiological maturation of the central nervous system with progression of gestation account for the differences between the brain injury patterns of full-term neonates and those of premature neonates. ${ }^{9}$ While term newborns with HIE predominantly show diffuse disease, cerebral-deep nuclear disease with prominent involvement of cerebral neocortex, hippocampus, and basal ganglia-thalamus, and deep nuclear-brainstem disease, ${ }^{10}$ cerebral white matter is chiefly involved in preterm newborns with HIE. ${ }^{9,11}$ This difference in brain injury patterns should be closely related to fetal brain development, as the organization and myelination of fetal brain begin after 6 months of gestation. Myelination of neuronal axons increases conduction speed, and oligodendrocytes are responsible for myelin synthesis in the central nervous system. Oligodendrocytes progenitor cells are formed in the ventricular zone after approximately 20 weeks of gestation, and these cells are vulnerable to oxidative stress. As preterm newborns before 30 weeks of gestation are with deficient myelination, white matter injury of the brain is a main form of brain injury in preterm babies. ${ }^{12-15}$

Diverse pregnancy disorders are associated with preterm birth, which refers to birth before 37 gestational weeks. Spontaneous preterm births are the results of premature labor or preterm premature rupture of membranes, and medically indicated preterm birth is frequently associated with clinical situations where maternal or fetal well-being can be compromised without medical intervention, as in preeclampsia or fetal growth restriction. ${ }^{16}$ Premature babies are vulnerable to various perinatal morbidities, and the frequency of short- and long-term complications such as neonatal respiratory distress syndrome and cerebral palsy $(\mathrm{CP})$ 
is significantly increased. ${ }^{17}$ This review will summarize the current understanding of white matter injury in premature newborns with special reference to its prenatal components in pathology and clinical significance.

\section{WHITE MATTER INJURY OF PREMATURITY}

In immature brains of preterm babies, white matter injuries occur as germinal matrix hemorrhage-intraventricular hemorrhage (GMH-IVH), periventricular leukomalacia (PVL), and diffuse white matter injury. ${ }^{18} \mathrm{GMH}-\mathrm{IVH}$ is a consequence of venous bleeding from thin-walled vessels in the germinal matrix, which easily propagates into the ventricle because of the anatomical relationship with the ventricles. GMH-IVH can evolve into permanent lesions such as porencephalic cyst and hydrocephalus. On the other hand, PVL occurs due to inadequate arterial blood supply to deep white matter, which leads to hypoxia and ischemia in the regions involved (Fig. 1). At the cellular level, PVL is associated with pancellular necrosis and surrounding edema. In diffuse white matter injury, a prominent feature is the loss of oligodendroglia and subsequent decrease in axonal myelination.

\section{CLINICAL FEATURES OF WHITE MATTER INJURY OF PREMATURITY}

Several cohort studies have assessed the risk factors of preterm white matter injury. ${ }^{19-21}$ Herzog et al..$^{22}$ examined the impact of

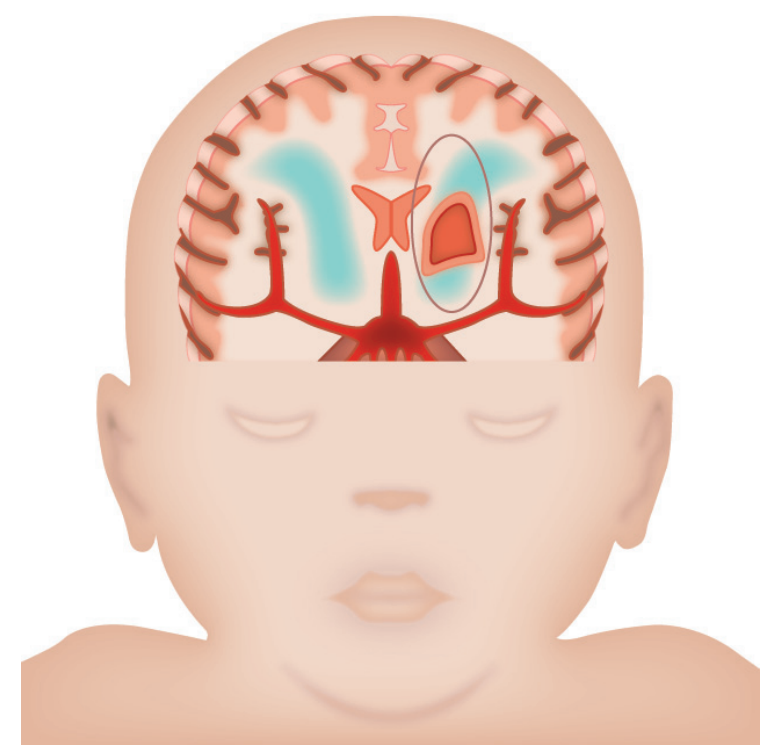

Fig. 1. Schematic representation of diffuse white matter injury (green) and cystic periventricular leukomalacia (circle) in a newborn brain. putative risk factors of PVL besides prematurity in the Slovenian National Perinatal Information System data and reported that maternal obesity and acute chorioamnionitis increase the risk of PVL more than prematurity does. Gagliardi et al..$^{23}$ analyzed a prospective singleton infant cohort ( $\mathrm{n}=2,085)$ between 23 and 31 weeks of gestational age born in six Italian regions (ACTION study). They looked at the relationships between pregnancy disorders associated with very preterm birth and neonatal outcomes. For the comparisons, the pregnancy disorders were divided into two categories: "disorders of placentation" (hypertensive disorders and fetal growth-restricted [FGR]) and "presumed infection/inflammation" (preterm labor and preterm prelabor rupture of membranes [PPROM]). The risk of mortality, bronchopulmonary dysplasia, and retinopathy of prematurity was higher in FGR infants, and the risk of intraventricular hemorrhage and PVL was lower than in newborns with infection/ inflammation disorders when adjusted for gestational age. ${ }^{23}$

An analysis of very preterm infants $(\mathrm{n}=753)$ surviving at least 7 days demonstrated cystic PVL in 9.2\%, and the incidence of PVL was highest (16\%) in newborns at 28 weeks of gestation. Prenatal inflammation before delivery and the development of PVL showed a strong correlation, and the intrauterine infection and premature rupture of membranes in combination conferred a much higher risk (22\%) of PVL. On the other hand, chronic fetal distress such as fetal growth retardation and preeclampsia was seldom followed by PVL ( $<2 \%$ risk). ${ }^{24}$ Another case-control study that analyzed preterm infants with PVL $(\mathrm{n}=95)$ and controls $(\mathrm{n}=245)$ showed an association between PVL and PPROM, gestational age at PPROM, prolonged rupture of membranes $(\mathrm{p}<.0001)$, administration of tocolytics, and antibiotics. In contrast, preeclampsia, hypertension, FGR, abnormal umbilical artery Doppler, and cesarean delivery in the absence of labor were less frequent. In logistic regression analysis, however, many of these lost statistical significance, while birth weight turned out to be significant. The overall findings suggested that PPROM and prolonged rupture of the membranes affect the neurodevelopmental outcome of the preterm fetus. ${ }^{25}$

\section{RADIOLOGIC FINDINGS OF WHITE MATTER INJURY OF PREMATURITY}

\section{Ultrasonography}

A developing fetal brain is rapidly changing during pregnancy. However, it is very challenging to monitor this important and rapidly changing fetal organ by conventional transabdominal ultrasonography. In this respect, transvaginal high-resolution 
ultrasound (US) and three-dimensional (3D) US turned out to be very helpful in the assessment of $3 \mathrm{D}$ configuration of fetal brain. 3D US is effective in the prenatal assessment of fetal brain anomalies, vascular malformations, and acquired insults. ${ }^{26}$

US examination has been widely used in the detection of brain lesions in fetuses and newborns. According to a prospective study that examined the frequency of echodensities in the periventricular white matter, basal ganglia, and thalamus of 124 fetuses with risk of preterm birth, echodensities were found in $66 \%$ of the cases by transvaginal US examination. The gestational age window of the fetuses was between 26 and 34 weeks, and all mothers were with either hypertensive disorders of pregnancy or preterm labor. The most frequent region was the periventricular area $(52 \%)$. At least $50 \%$ of the periventricular echodensities persisted after delivery. The study showed that echodensities in several areas of the brain are a relatively common finding in high-risk fetuses. ${ }^{27}$

Padilla-Gomes $e t ~ a l .^{28}$ compared the frequency of transient periventricular echodensities (TPE), PVL, and hemorrhagic brain lesions in FGR preterm babies and in appropriate-forgestational-age (AGA) babies. The gestational age of the study population ranged between 24 and 34 weeks, and brain changes were assessed by US at day 3 (US-I), 2 weeks (US-II) after delivery, and term-equivalent age (US-III). They found a higher prevalence of TPE at US-I and PVL at US-II and US-III in FGR neonates. Based on the results, the investigators proposed that fetal growth restriction is associated with an increased prevalence of white matter damage (WMD) in US brain scans of preterm babies. ${ }^{28}$

A series of EPIPAGE cohort of French studies confirmed brain abnormalities in very preterm infants according to clinical parameters such as gestational age, plurality, and fetal growth restriction. Based on cranial US findings, the frequencies of WMD, major WMD, cystic PVL, periventricular hemorrhage, and intraventricular hemorrhage were $21 \%, 8 \%, 5 \%, 3 \%$, and $3 \%$, respectively. The risk of WMD showed an inverse relationship with gestational age, while the incidence of cystic PVL in FGR babies and in AGA babies did not differ. ${ }^{29}$ Based on the neonatal US findings, $17 \%$ of children with grade III intraventricular hemorrhage and a quarter of children with WMD developed cerebral palsy. In contrast, CP was found in only $4 \%$ of children with unremarkable US findings. ${ }^{30}$

Certain placental histopathological findings are associated with fetal and perinatal brain injuries, and brain US findings were shown to be associated with placental histopathological changes consistent with placental underperfusion or inflammation. A prospective analysis of fetuses ( $n=77$; gestational age, 26 to 34 weeks) demonstrated that moderate brain echogenicity changes such as periventricular echodensity grade IB and intraventricular echodensity grade II and III are found in cases with uteroplacental underperfusion and inflammation. In particular, placental lesions were present in all cases with grade IB periventricular echodensity. ${ }^{31}$

\section{Magnetic resonance imaging}

The whole fetal brain structure can also be observed by magnetic resonance imaging (MRI) in the second half of pregnancy. ${ }^{26}$ Acute chorioamnionitis is a histological surrogate of intrauterine infection and inflammation and is a component of fetal inflammatory response. This is more commonly found in preterm birth. Anblagan et $a l^{32}$ examined placental histology and neonatal brain MRI data in a cohort of preterm babies $(\mathrm{n}=90)$ using tract-based spatial statistics to compare fractional anisotropy (FA) data and computational morphometry analysis. The volumes of whole brain, tissue compartments, and cerebrospinal fluid were assessed to determine if acute chorioamnionitis is a risk factor for preterm brain injury. The study decreased FA in the genu, cingulum cingulate gyri, centrum semiovale, inferior longitudinal fasciculi, limbs of the internal capsule, external capsule, and cerebellum in cases with acute chorioamnionitis ( $\mathrm{p}<.05$, corrected). This suggests that prenatal white matter injury occurs in a substantial proportion of preterm infants. ${ }^{32}$

Banovic et $a l^{33}$ analyzed the incidence of fetal brain injury by MRI in the cases of preterm labor, preterm prelabor rupture of the membranes, and FGR and compared fetal brain MRI with other antenatal monitoring tools such as US and biophysical profile. They looked at both immediate neonatal outcome and longterm neurodevelopmental handicap at 24 months in 70 cases. While no correlation was found between abnormal MRI and other surveillance tools or immediate neonatal outcome, binary logistic regression showed that fetal brain MRI is the most powerful indicator of long-term neurodevelopmental handicap. ${ }^{33}$ A review of prenatal MRI data by Doneda et al. ${ }^{34}$ also suggested that transient venous hypertension in utero is responsible for frontal PVL. The investigators looked for anomalies distributed in the deep medullary vein territory in 78 fetuses with unequivocal cerebral clastic lesions. ${ }^{34}$

\section{Pathophysiology of white matter injury of prematurity}

The major reasons for the predominant involvement of cerebral white matter in preterm babies are considered to be the vulnerability of premyelinating oligodendrocytes to reactive oxygen species and cerebral anatomical constitution. Preterm newborns have impaired autoregulation of cerebral blood flow, and there 
are vascular end zones and border zones. ${ }^{35,36}$ Regarding the etiology of white matter injury of prematurity, accumulated evidence strongly indicates that there are two main pathways involved. One is the ischemic pathway, the other is the inflammatory pathway, and these two pathways can be synergistic. ${ }^{37-39}$ The incidence of hypoxic ischemic brain injuries is higher in fetuses exposed to maternal inflammation and infection. ${ }^{40,41}$

\section{Ischemic pathway}

The ischemic pathway is mainly related to excitotoxicity and oxidative stress. ${ }^{42-44}$ Excitotoxicity is due to depolarization following energy failure of the cells. Depolarization leads to excessive glutamate discharge and calcium influx into the cells, as a result of which nitric oxide synthase is activated. Cellular injury is then induced by increased nitric oxide production. Reperfusion injury following H-I cycles imposes oxidative stress on the cells. ${ }^{45}$ Premyelinating oligodendrocytes are more susceptible to oxidative stress than fully differentiated oligodendrocytes are because they lack antioxidant enzymes such as superoxide dismutase and glutathione peroxidase. ${ }^{38,46}$

\section{Inflammatory pathway}

A substantial role for inflammatory pathway related to infection and inflammation has been described. Several studies have shown that intra-amniotic infection and inflammation are causative factors of perinatal and long-term complications. ${ }^{47-49}$

\section{Antenatal versus postnatal origin of white matter injury of prematurity}

While it is generally considered that perinatal brain injury is a consequence of intrapartum or postpartum events, there is substantial evidence that a certain proportion of brain injuries has antenatal components. ${ }^{32,50}$ An examination of 58 stillborn fetuses for the presence of GMH, pontosubicular necrosis (PSN), and PVL revealed at least one lesion in $40 \%$ of cases, clearly indicating that GMH and PVL can occur in utero. The investigators have also found evidence for the prenatal occurrence of GMH in some cases by US examination and pointed out that PVL and PSN can occur in utero as well. ${ }^{51}$ Nakamura et al..$^{52}$ have confirmed cystic brain lesions in two autopsy cases. One was a donor fetus in twinto-twin transfusion syndrome, and the other was a case of thanatophoric dwarfism. Chronic PVL was found in the second case. The findings observed in these cases imply that cerebral circulatory disturbance is a pathogenetic mechanism of in utero brain injuries. ${ }^{52}$

\section{Placental pathology in white matter injury of prematurity}

Several studies have documented the importance of placental pathology in white matter injury of prematurity. Chang et al. ${ }^{53}$ looked at neuropathological findings in 37 third-trimester fetal deaths in conjunction with their placental lesions. There was a correlation between neuronal karyorrhexis or white matter gliosis and severe placental inflammation, and histologically proven PVL was found in two cases. ${ }^{53}$ An analysis of 167 preterm babies born between 23 and 34 weeks of gestation revealed a significant association between PVL and chronic deciduitis. ${ }^{54}$ In preterm infants, antepartum bleeding of placenta previa is a risk factor for PVL. ${ }^{55}$ When Wharton et al. ${ }^{56}$ performed a case-control study to examine the relationship between PVL and chorioamnionitis in very low-birth-weight infants, severe umbilical cord inflammation was found to be a risk factor of PVL. Kumazaki et al. ${ }^{57}$ reported massive retroplacental hemorrhage, extensive infarction, and severe perivillous fibrin deposition in preterm infants with ante- or peripartum PVL. The study findings suggest an association between poor placental perfusion and white matter injury of prematurity.

\section{Experimental models}

Experimental studies have been done to determine if in utero brain injuries are induced in animals. Regarding the consequences of fetal brain injury following in utero hypoxia and ischemia, studies have documented both pathological lesions of the brain and the derangement of motor function in rabbits akin to human CP. ${ }^{58,59}$ Brain lesions similar to human white matter injury have been easier to reproduce in gyrencephalic animals such as rabbits, dogs, and sheep than in rodents. White matter injuries in models of H-I pathway by hypoperfusion are characterized by more diffuse microglial response, while the experimental simulation of inflammatory pathway using lipopolysaccharide induces lesions with more prominent inflammatory cell infiltration. ${ }^{60}$ Rabbits have more traits that can be helpful in studies than other animal species do. Principally, their motor development occurs in the perinatal period, as is the case with humans. ${ }^{61}$

Using a model of placental insufficiency, Buser et al..$^{62}$ demonstrated selective patterns of gray and white matter injury after global H-I in fetal rabbits. Gray matter injury predominated following H-I at embryonic day 22 (E22), while white matter injury was minimal. They also observed that, following H-I at E25, there was an increased acute white matter injury instead. Consequently, white matter atrophy was detected at E29 in preterm rabbits after $\mathrm{H}-\mathrm{I}$ at E25, while it was not detected following $\mathrm{H}-\mathrm{I}$ at E22. As oligodendrocyte progenitors density increases 
between E24 and E25 in rabbit forebrain, the investigators proposed that it explains the differences in susceptibility to gray and white matter injury and that this may be the case in white matter injury of preterm newborns. ${ }^{62}$

Derrick et al..$^{63}$ induced motor deficits in rabbit fetuses using a model of in utero placental insufficiency that were akin to motor deficits in human $\mathrm{CP}$ in premature and term babies. Surviving preterm rabbit fetuses (67\%-70\% gestation) subjected to persistent global hypoxia had hypertonia and abnormal motor control. At postnatal day 1, the pups of hypoxic groups had impaired locomotion, motor reflex, sucking, and swallowing. Histological examination revealed acute injury to motor pathways in the subcortical region. ${ }^{63}$ In a following study, Derrick et al. ${ }^{61}$ modeled sustained and repetitive in utero $\mathrm{H}-\mathrm{I}$ resembling placental abruption and labor in the pregnant rabbit. They showed that sustained H-I at E22 and at E25 induces fetal death and other deficits in the surviving animals. Magnetic resonance imaging (MRI) suggested that injury in the internal capsule white matter is responsible for a part of the hypertonia. ${ }^{61}$

The role of intrauterine infection in fetal brain injuries also has been examined in several animal models. ${ }^{64-66}$ Field $e t$ al. ${ }^{67}$ introduced Gardnerella vaginalis into the pregnant rabbit uterus at E20 or E21 by hysteroscopy to see the effects of intrauterine infection on feto-maternal outcome. Both amnionitis and deciduitis were induced by $G$. vaginalis inoculation, but maternal fever and preterm delivery surprisingly were not. In the fetuses, however, intrauterine infection with $G$. vaginalis decreased the live birth rate, and the fetuses exposed to deciduitis had lower birth weight. In addition, the $G$. vaginalis-inoculated study group had significantly higher frequency of serious brain injury than the control group (60\% vs $0 \%$ ). The study findings indicate that $G$. vaginalis has more pathological impact in the rabbit fetus than in the mother. ${ }^{67}$ There is further experimental evidence that intrauterine infection leads to WMD in utero. Yoon et al.$^{68}$ introduced Eschericbia coli into the pregnant rabbit uterus from E20 to E21, maintained the pregnancy for additional 5 to 6 days by antibiotic treatment, and examined the brains of fetuses and the placentas. Histologically proven white matter pathology was found in 12 fetuses of $10 \mathrm{E}$. coli-inoculated rabbits, but not in the control group $(\mathrm{p}<.05)$. All of the rabbits with white matter pathology were associated with intrauterine infection. ${ }^{68}$ Intrauterine endotoxin administration also induced microstructural changes in the white matter of rabbit newborns, which were detected by diffusion tensor MRI. Term newborn rabbits prenatally exposed to endotoxin at E28 showed decreased FA in periventricular white matter. Brain sections disclosed more frequent activated microglial cells, which may explain the change in diffusivity. ${ }^{69}$

\section{CONCLUSION}

Despite the marked improvement in postnatal care during recent decades, there has been no great success in reducing the incidence of white matter injuries in preterm newborns. This indicates that the major targets for prevention of brain injuries are in utero events especially in preterm newborns. In this review, I have summarized both the pathophysiological and clinical aspects of white matter injury of prematurity. To prevent and improve the clinical outcome of this potentially catastrophic event, more vigilant prenatal monitoring and further studies to find more powerful prenatal biomarkers of fetal brain white matter injury are urgent.

\section{Conflicts of Interest}

No potential conflict of interest relevant to this article was reported.

\section{Acknowledgments}

The author is very grateful to Ms. So Won Kim for her excellent assistance in manuscript preparation and editing.

\section{REFERENCES}

1. Nelson KB, Ellenberg JH. Neonatal signs as predictors of cerebral palsy. Pediatrics 1979; 64: 225-32.

2. Nelson KB, Ellenberg JH. Apgar scores as predictors of chronic neurologic disability. Pediatrics 1981; 68: 36-44.

3. Graham EM, Ruis KA, Hartman AL, Northington FJ, Fox HE. A systematic review of the role of intrapartum hypoxia-ischemia in the causation of neonatal encephalopathy. Am J Obstet Gynecol 2008; 199: 587-95.

4. Lai MC, Yang SN. Perinatal hypoxic-ischemic encephalopathy. J Biomed Biotechnol 2011; 2011: 609813.

5. Martinez-Biarge M, Diez-Sebastian J, Wusthoff CJ, Mercuri E, Cowan FM. Antepartum and intrapartum factors preceding neonatal hypoxic-ischemic encephalopathy. Pediatrics 2013; 132: e952-9.

6. Blumberg RM, Cady EB, Wigglesworth JS, McKenzie JE, Edwards $\mathrm{AD}$. Relation between delayed impairment of cerebral energy metabolism and infarction following transient focal hypoxia-ischaemia in the developing brain. Exp Brain Res 1997; 113: 130-7.

7. Gilland E, Bona E, Hagberg H. Temporal changes of regional glucose use, blood flow, and microtubule-associated protein 2 immunos- 
taining after hypoxia-ischemia in the immature rat brain. J Cereb Blood Flow Metab 1998; 18: 222-8

8. Ferriero DM. Neonatal brain injury. N Engl J Med 2004; 351: 1985-95.

9. Gopagondanahalli KR, Li J, Fahey MC, et al. Preterm hypoxic-ischemic encephalopathy. Front Pediatr 2016; 4: 114.

10. Yokochi K, Fujimoto S. Magnetic resonance imaging in children with neonatal asphyxia: correlation with developmental sequelae. Acta Paediatr 1996; 85: 88-95.

11. Murray AL, Thompson DK, Pascoe L, et al. White matter abnormalities and impaired attention abilities in children born very preterm. Neuroimage 2016; 124(Pt A): 75-84.

12. Back SA, Luo NL, Borenstein NS, Levine JM, Volpe JJ, Kinney HC. Late oligodendrocyte progenitors coincide with the developmental window of vulnerability for human perinatal white matter injury. J Neurosci 2001; 21: 1302-12.

13. Back SA, Luo NL, Borenstein NS, Volpe JJ, Kinney HC. Arrested oligodendrocyte lineage progression during human cerebral white matter development: dissociation between the timing of progenitor differentiation and myelinogenesis. J Neuropathol Exp Neurol 2002; 61: 197-211.

14. van Tilborg E, Heijnen CJ, Benders MJ, et al. Impaired oligodendrocyte maturation in preterm infants: potential therapeutic targets. Prog Neurobiol 2016; 136: 28-49.

15. Wellmann S, Buhrer C, Schmitz T. Focal necrosis and disturbed myelination in the white matter of newborn infants: a tale of too much or too little oxygen. Front Pediatr 2014; 2: 143.

16. Romero R, Espinoza J, Kusanovic JP, et al. The preterm parturition syndrome. BJOG 2006; 113 Suppl 3: 17-42.

17. Marlow N, Wolke D, Bracewell MA, Samara M; EPICure Study Group. Neurologic and developmental disability at six years of age after extremely preterm birth. N Engl J Med 2005; 352: 9-19.

18. Folkerth RD. Neuropathologic substrate of cerebral palsy. J Child Neurol 2005; 20: 940-9.

19. Bolisetty S, Dhawan A, Abdel-Latif M, et al. Intraventricular hemorrhage and neurodevelopmental outcomes in extreme preterm infants. Pediatrics 2014; 133: 55-62.

20. Cooper MS, Mackay MT, Fahey M, et al. Seizures in children with cerebral palsy and white matter injury. Pediatrics 2017; 139: e20162975.

21. Wagenaar N, Chau V, Groenendaal F, et al. Clinical risk factors for punctate white matter lesions on early magnetic resonance imaging in preterm newborns. J Pediatr 2017; 182: 34-40.e1.

22. Herzog M, Cerar LK, Sršen TP, Verdenik I, Lučovnik M. Impact of risk factors other than prematurity on periventricular leukomalacia: a population-based matched case control study. Eur J Obstet Gynecol Reprod Biol 2015; 187: 57-9.

23. Gagliardi L, Rusconi F, Da Frè M, et al. Pregnancy disorders leading to very preterm birth influence neonatal outcomes: results of the population-based ACTION cohort study. Pediatr Res 2013; 73: 794801.

24. Zupan V, Gonzalez P, Lacaze-Masmonteil T, et al. Periventricular leukomalacia: risk factors revisited. Dev Med Child Neurol 1996; 38: 1061-7.

25. Bauer M, Fast C, Haas J, Resch B, Lang U, Pertl B. Cystic periventricular leukomalacia in preterm infants: an analysis of obstetric risk factors. Early Hum Dev 2009; 85: 163-9.

26. Pooh RK. Imaging diagnosis of congenital brain anomalies and injuries. Semin Fetal Neonatal Med 2012; 17: 360-76.

27. Rosier-van Dunné FM, van Wezel-Meijler G, Odendaal HJ, van Geijn HP, de Vries JI. Changes in echogenicity in the fetal brain: a prevalence study in fetuses at risk for preterm delivery. Ultrasound Obstet Gynecol 2007; 29: 644-50.

28. Padilla-Gomes NF, Enríquez G, Acosta-Rojas R, Perapoch J, Hernandez-Andrade E, Gratacos E. Prevalence of neonatal ultrasound brain lesions in premature infants with and without intrauterine growth restriction. Acta Paediatr 2007; 96: 1582-7.

29. Larroque B, Marret S, Ancel PY, et al. White matter damage and intraventricular hemorrhage in very preterm infants: the EPIPAGE study. J Pediatr 2003; 143: 477-83.

30. Ancel PY, Livinec F, Larroque B, et al. Cerebral palsy among very preterm children in relation to gestational age and neonatal ultrasound abnormalities: the EPIPAGE cohort study. Pediatrics 2006; 117: 828-35.

31. Rosier-van Dunné FM, van Wezel-Meijler G, Kaschula RO, Wranz PA, Odendaal HJ, de Vries JI. Placental histology related to fetal brain sonography. Arch Dis Child Fetal Neonatal Ed 2011; 96: F53-8.

32. Anblagan D, Pataky R, Evans MJ, et al. Association between preterm brain injury and exposure to chorioamnionitis during fetal life. Sci Rep 2016; 6: 37932.

33. Banović V, Škrablin S, Banović M, Radoš M, Gverić-Ahmetašević S, Babić I. Fetal brain magnetic resonance imaging and long-term neurodevelopmental impairment. Int J Gynaecol Obstet 2014; 125: 237-40.

34. Doneda C, Righini A, Parazzini C, Arrigoni F, Rustico M, Triulzi F. Prenatal MR imaging detection of deep medullary vein involvement in fetal brain damage. AJNR Am J Neuroradiol 2011; 32: E146-9.

35. Alderliesten T, Lemmers PM, Smarius JJ, van de Vosse RE, Baerts $\mathrm{W}$, van Bel F. Cerebral oxygenation, extraction, and autoregulation in very preterm infants who develop peri-intraventricular hemorrhage. J Pediatr 2013; 162: 698-704.e2.

36. Wong FY, Leung TS, Austin T, et al. Impaired autoregulation in preterm infants identified by using spatially resolved spectroscopy. Pediatrics 2008; 121: e604-11.

37. Deng W. Neurobiology of injury to the developing brain. Nat Rev 
Neurol 2010; 6: 328-36.

38. Khwaja O, Volpe JJ. Pathogenesis of cerebral white matter injury of prematurity. Arch Dis Child Fetal Neonatal Ed 2008; 93: F153-61.

39. Volpe JJ. Brain injury in premature infants: a complex amalgam of destructive and developmental disturbances. Lancet Neurol 2009; 8: 110-24.

40. Rezaie P, Dean A. Periventricular leukomalacia, inflammation and white matter lesions within the developing nervous system. Neuropathology 2002; 22: 106-32.

41. Zhao J, Chen Y, Xu Y, Pi G. Effect of intrauterine infection on brain development and injury. Int J Dev Neurosci 2013; 31: 543-9.

42. Back SA, Rosenberg PA. Pathophysiology of glia in perinatal white matter injury. Glia 2014; 62: 1790-815.

43. Burd I, Welling J, Kannan G, Johnston MV. Excitotoxicity as a common mechanism for fetal neuronal injury with hypoxia and intrauterine inflammation. Adv Pharmacol 2016; 76: 85-101.

44. Perrone S, Tataranno LM, Stazzoni G, Ramenghi L, Buonocore G. Brain susceptibility to oxidative stress in the perinatal period. J Matern Fetal Neonatal Med 2015; 28 Suppl 1: 2291-5.

45. Back SA, Han BH, Luo NL, et al. Selective vulnerability of late oligodendrocyte progenitors to hypoxia-ischemia. J Neurosci 2002; 22: 455-63.

46. Back SA, Luo NL, Mallinson RA, et al. Selective vulnerability of preterm white matter to oxidative damage defined by F2-isoprostanes. Ann Neurol 2005; 58: 108-20.

47. Boyle AK, Rinaldi SF, Norman JE, Stock SJ. Preterm birth: Inflammation, fetal injury and treatment strategies. J Reprod Immunol 2017; 119: 62-6.

48. Malaeb S, Dammann O. Fetal inflammatory response and brain injury in the preterm newborn. J Child Neurol 2009; 24: 1119-26.

49. Yuan TM, Sun Y, Zhan CY, Yu HM. Intrauterine infection/inflammation and perinatal brain damage: role of glial cells and Toll-like receptor signaling. J Neuroimmunol 2010; 229: 16-25.

50. Murthy V, Kennea NL. Antenatal infection/inflammation and fetal tissue injury. Best Pract Res Clin Obstet Gynaecol 2007; 21: 479-89.

51. Skullerud K, Skjaeraasen J. Clinicopathological study of germinal matrix hemorrhage, pontosubicular necrosis, and periventricular leukomalacia in stillborn. Childs Nerv Syst 1988; 4: 88-91.

52. Nakamura Y, Fujiyoshi Y, Fukuda S, et al. Cystic brain lesion in utero. Acta Pathol Jpn 1986; 36: 613-20.

53. Chang KT, Keating S, Costa S, Machin G, Kingdom J, Shannon P. Third-trimester stillbirths: correlative neuropathology and placental pathology. Pediatr Dev Pathol 2011; 14: 345-52.

54. Maleki Z, Bailis AJ, Argani CH, Askin FB, Graham EM. Periventricular leukomalacia and placental histopathologic abnormalities. Obstet Gynecol 2009; 114: 1115-20.
55. Oda N, Takeuchi K, Tanaka A, Maruo T. Obstetric risk factors associated with the development of periventricular leukomalacia in preterm infants born to mothers complicated by placenta previa. Fetal Diagn Ther 2008; 24: 345-8.

56. Wharton KN, Pinar H, Stonestreet BS, et al. Severe umbilical cord inflammation-a predictor of periventricular leukomalacia in very low birth weight infants. Early Hum Dev 2004; 77: 77-87.

57. Kumazaki K, Nakayama M, Sumida Y, et al. Placental features in preterm infants with periventricular leukomalacia. Pediatrics 2002; 109: 650-5.

58. Drobyshevsky A, Derrick M, Luo K, et al. Near-term fetal hypoxiaischemia in rabbits: MRI can predict muscle tone abnormalities and deep brain injury. Stroke 2012; 43: 2757-63.

59. Drobyshevsky A, Luo K, Derrick M, et al. Motor deficits are triggered by reperfusion-reoxygenation injury as diagnosed by MRI and by a mechanism involving oxidants. J Neurosci 2012; 32: 5500-9.

60. Hagberg H, Peebles D, Mallard C. Models of white matter injury: comparison of infectious, hypoxic-ischemic, and excitotoxic insults. Ment Retard Dev Disabil Res Rev 2002; 8: 30-8.

61. Derrick M, Drobyshevsky A, Ji X, Tan S. A model of cerebral palsy from fetal hypoxia-ischemia. Stroke 2007; 38(2 Suppl): $731-5$.

62. Buser JR, Segovia KN, Dean JM, et al. Timing of appearance of late oligodendrocyte progenitors coincides with enhanced susceptibility of preterm rabbit cerebral white matter to hypoxia-ischemia. J Cereb Blood Flow Metab 2010; 30: 1053-65.

63. Derrick M, Luo NL, Bregman JC, et al. Preterm fetal hypoxia-ischemia causes hypertonia and motor deficits in the neonatal rabbit: a model for human cerebral palsy? J Neurosci 2004; 24: 24-34.

64. Burd I, Balakrishnan B, Kannan S. Models of fetal brain injury, intrauterine inflammation, and preterm birth. Am J Reprod Immunol 2012; 67: 287-94.

65. Duncan JR, Cock ML, Scheerlinck JP, et al. White matter injury after repeated endotoxin exposure in the preterm ovine fetus. Pediatr Res 2002; 52: 941-9.

66. Girard S, Kadhim H, Roy M, et al. Role of perinatal inflammation in cerebral palsy. Pediatr Neurol 2009; 40: 168-74.

67. Field NT, Newton ER, Kagan-Hallet K, Peairs WA. Perinatal effects of Gardnerella vaginalis deciduitis in the rabbit. Am J Obstet Gynecol 1993; 168(3 Pt 1): 988-94.

68. Yoon BH, Kim CJ, Romero R, et al. Experimentally induced intrauterine infection causes fetal brain white matter lesions in rabbits. Am J Obstet Gynecol 1997; 177: 797-802.

69. Saadani-Makki F, Kannan S, Makki M, et al. Intrauterine endotoxin administration leads to white matter diffusivity changes in newborn rabbits. J Child Neurol 2009; 24: 1179-89. 